an incidence around 1/100 000/year. We studied the characteristics and outcome in PICU patients with ICH.

Methods Children with ICH admitted to PICU during 2000-2010, were retrospectively studied. Clinical information was abstracted via chart review.

Results 21 consecutive cases, aged $5.6 \pm 4.5$ years, 12 girls, were analyzed. $70 \%$ of the children presented with vomiting, $55 \%$ with seizures, 38\% with headache and $9.6 \%$ with focal neurological signs. Mean Glasgow Coma Scale (GCS) before intubation was $7.33 \pm 2.45$. In $66.6 \%$ emergent evacuation of hematoma or hydrocephalus at admission was performed. $23.5 \%$ had an arteriovenous malformation (AVM) and 15\% of these children underwent embolization for AVM obliteration. Mortality was found 19\%. Patients who died had lower GCS (4.75 \pm 2.06 vs. $7.9 \pm 2.16), \mathrm{P}<0.05$, higher

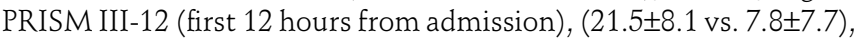
$\mathrm{P}<0.005$, higher PRISM III-24 (next 12 hours), (17.2 \pm 8.3 vs. $5.2 \pm 5.1$ ), $\mathrm{P}<0.001$, and longer $\alpha \mathrm{PTT}, \mathrm{P}<0.01$ than those who survived. Patients who needed inotropic support the 1rst day of PICU stay had 12 times greater mortality than children who didn't need inotropic support. Among survivors $68.7 \%$ presented neurologic deficit at PICU discharge. Children with neurologic deficit had lower GCS (6.8 \pm 1.6 vs. $10 \pm 1.5), \mathrm{P}<0.005$ than those without deficit.

Conclusions As outcome is dismal in children with ICH and critical illness at presentation, low GCS, high PRISM III and need for inotropic support, prompt diagnosis seems essential to improve prognosis in these children.

\section{USEFULLNESS OF THE PRISM III SCORE TO PREDICT OUTCOME IN CRITICALLY ILL CHILDREN WITH VAP}

doi:10.1136/archdischild-2012-302724.0811

S Stabouli, E Volakli, A Violaki, A Tsolaki, M Dimitriadou, K Skoumis, M Sdougka. PICU, Hippokration Hospital, Thessaloniki, Greece

Background and Aims Ventilator-associated pneumonia (VAP) is associated with increased length of stay and adverse outcomes in PICU patients. In a retrospective study, we examined if PRISM III score at admission or at the day of VAP development could better predict the outcome in patients with VAP.

Methods The medical records of PICU patients admitted to a 8-Bed PICU of a tertiary-care hospital from January-December 2011 were reviewed. Clinical data, PRISM III score at admission or at the day of VAP development were recorded. VAP was diagnosed according to CDC criteria.

Results 27 patients, mean age $4.40 \pm 4.23$ years, $59.3 \%$ boys, developed VAP. 4 patients presented 2 VAP episodes. Mean PRISM III score at admission was 10.19 \pm 7.65 , at the day of first VAP episode $7.31 \pm 6.94$, and at the day of 2 nd VAP episode $4.75 \pm 3.60$. The receiver operator characteristic curve (ROC) analysis showed that PRISM III at admission could better predict mortality in PICU patients with VAP than PRISM III at the day of VAP episode. (Figure 1).

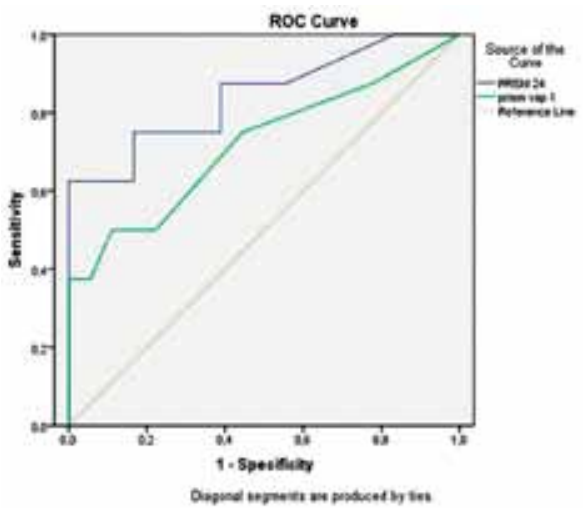

Abstract 811 Figure 1
The area under the curve was found 0.85 (asymptotic 95\%CI 0.59 to $1, \mathrm{P}<0.01)$ for PRISM III at admission and 0.72 (95\%CI 0.48 to $0.95, \mathrm{P}=0,081$ ) for PRISM III at VAP episode.

Conclusions PRISM III at admission could better predict mortality in PICU patients with VAP than PRISM III at the day of VAP episode suggesting that VAP may not independently affect mortality.

\section{CARDIOPULMONARY ARREST IN PEDIATRIC EMERGENCY CARE AND INTENSIVE CARE: A MULTICENTER STUDY IN TURKEY}

doi:10.1136/archdischild-2012-302724.0812

${ }^{1}$ T Kendirli, ${ }^{2} \mathrm{~N}$ Erkek, ${ }^{3} \mathrm{~T}$ Köroğlu, ${ }^{4 B}$ Bayrakçı, ${ }^{5} \mathrm{~A}$ güzel, ${ }^{6} \mathrm{~A}$ Çıtak, ${ }^{7} \mathrm{D}$ Demirkol, ${ }^{8} \mathrm{H}$ Ağın, ${ }^{9} \mathrm{AE}$ Arslanköylü, ${ }^{10} \mathrm{NO}$ Kutlu, ${ }^{11}{ }^{1}$ Paksu, ${ }^{12} \mathrm{AB}$ Anıl, ${ }^{13} \mathrm{G}$ Kalkan, ${ }^{14} \mathrm{D}$ Yıldızdaş, ${ }^{15} \mathrm{M}$ Duman, ${ }^{16} \mathrm{R}$ Dündaröz, ${ }^{11} \mathrm{~N}$ Aşılıoğlu, ${ }^{17} \mathrm{~A}$ Yaman, ${ }^{4} \mathrm{~S}$ Kesici, ${ }^{18} \mathrm{D}$ Tekin, ${ }^{19} \mathrm{O}$ Dursun, ${ }^{17} \mathrm{C}$ Ödek, ${ }^{20} \mathrm{C}$ Ateş, ${ }^{21} \mathrm{HL}$ Yılmaz, ${ }^{17} \mathrm{E}$ İnce, ${ }^{7} \mathrm{M}$ Karaböcüoğlu. ${ }^{1}$ Pediatric ICU, Ankara University; ${ }^{2} \mathrm{Dr}$. Sami Ulus Hospital, Ankara; ${ }^{3}$ Dokuz Eylül University, Izmir; ${ }^{4}$ Pediatric ICU, Hacetepe University, Faculty of Medicine, Ankara; ${ }^{5}$ Pediatric Emergency Care, Ondokuz Mayis University, Samsun; ${ }^{6}$ Pediatric ICU, Istanbul University Istanbul Medical Faculty; ${ }^{7}$ Pediatric ICU, Bezmialem University, Istanbul; ${ }^{8}$ Pediatric ICU, Behçet Uz Children's Hospital, Izmir; ${ }^{9}$ Pediatric ICU, Mersin University, Mersin; ${ }^{10}$ Pediatric ICU, Meram Faculty of Medicine, Konya; ${ }^{11}$ Pediatric ICU, Ondokuz Mayis University, Samsun; ${ }^{12}$ Pediatric ICU, Tepecik Children's Hospital, Izmir; ${ }^{13}$ Pediatric ICU, Gazi University Faculty of Medicine, Ankara; ${ }^{14}$ Pediatric ICU, Çukurova Faculty of Medicine, Adana; ${ }^{15}$ Pediatric emergency Care, Dokuz Eylül University, Izmir; ${ }^{16}$ Pediatric Emergency Care, Bezmialem University, Istanbul; ${ }^{17}$ Pediatric ICU; ${ }^{18}$ Pediatric Emergency Care, Ankara University, Faculty of Medicine, Ankara; ${ }^{19}$ Pediatric ICU, Akdeniz University, Antalya; ${ }^{20}$ Biostatistics, Ankara University, Faculty of Medicine, Ankara; ${ }^{21}$ Pediatric Emergency Care, Çukurova University Faculty of Medicine, Adana, Turkey

Background and Aim The most cause of cardiopulmonary arrest (CPA) is respiratory system disorders. Usually the surive from CPA is $30 \%$ in hospital and under $10 \%$ in out of hospital. The aim of this study, the cause of CPA, applications and results of CPA in pediatric ICU and emergency care in Turkey.

Methods This study conducted between January 15 and July 15, 2011, multicenter, prospective, observational from Turkey.

Results We enrolled 239 children whose CPA developed. Fifty-four percent of all patients were boy and their mean age were $42.4 \pm 58.1$ months. The causes of CPA were respiratory failure in $49.8 \%$, sepsis in $301 . \%$, cardiac disease in $21.3 \%$ and rhythm disorders in $8.8 \%$. The place of CPA occurred were PICU in $68.6 \%$, services in $18 \%$, out of hospital in $10 \%$ and emergency care in $3.3 \%$ of patients whose CPA developed. Adrenalin was performed in 221, defibrillation in 16 and automatic external defibrillation in patients. Mean resuscitation time was $30.7 \pm 23.6$ minutes. Return percent after first resuscitaiton application was $44.8 \%$. We check to mortality rate after first resuscitation $43.3 \%$ in PICU, $41.9 \%$ in services, $50 \%$ in Emergency Care, $41.7 \%$ at out of hospital ( $p=0.539$ ). The $83 \%$ of them were unconsciousness, renal replacement therapy was applicated in 16 patients. After first resuscitation, 54.2 patient survived and neurologic sequele was in $32 \%$ of them.

Conclusion Mortality and morbidity are higher either hosptial and out of hospital CPA, therefore prevention to CPA and well resuscitation applications are very important.

\section{PALLIETERBURGHT: DEVELOPMENT OF A HIGH DEPENDENCE TRANSITIONAL CARE UNIT}

doi:10.1136/archdischild-2012-302724.0813

${ }^{1} \mathrm{M}$ Smit-van den Berg, ${ }^{1} \mathrm{C}$ Joosen, ${ }^{2} \mathrm{D}$ Tibboel, ${ }^{1} \mathrm{E}$ Ista, ${ }^{2} \mathrm{~S}$ Gischler. ${ }^{1} P I C U ;$; ${ }^{2} \mathrm{PICU}$ and Department of Pediatric Surgery, Erasmus MC - Sophia Children's Hospital, Rotterdam, The Netherlands

Background Ongoing advances in paediatric intensive care led to increased survival, with increased morbidity and long-lasting sequelae. 